\title{
Avaliação microbiológica de alimentos isentos de registro no Ministério da Saúde
}

\author{
Microbiological analysis of foods exempt of legal \\ registration procedures
}

\author{
Rafaela Gomes Ferrari'; Sabine Murakami Winkler²; \\ Tereza Cristina Rocha Moreira de Oliveira ${ }^{3 *}$
}

\section{Resumo}

O objetivo deste trabalho foi avaliar o padrão higiênico-sanitário de alimentos comercializados na Região de Londrina cadastrados no Ministério da Saúde, porém, dispensados de registro, conforme a RDC $\mathrm{n}^{\circ}$. 23 da Agência Nacional de Vigilância Sanitária (ANVISA). Os alimentos foram escolhidos de acordo com as sugestões da Vigilância Sanitária de Londrina, PR, que levou em consideração o risco epidemiológico. Os padrões microbiológicos foram avaliados conforme a RDC nº 12 da ANVISA. Contagens de E. coli e S. aureus acima do permitido foram observadas respectivamente em $11(18,3 \%)$ e $13(21,6 \%)$ dos 60 alimentos analisados. Os demais resultados microbiológicos estavam dentro do estabelecido pela RDC $\mathrm{n}^{\circ}$. 12. Ficou clara a necessidade de maior fiscalização do processamento e armazenagem de vários alimentos analisados, em especial, sorvetes, massas recheadas, pães de queijo, lasanha, doces com creme e salgados recheados. Esses resultados serão encaminhados às Vigilâncias Regional e Municipal alertando sobre a real potencialidade desses alimentos veicularem doenças e na intenção de abrir uma discussão sobre a liberação ou não de registro desses alimentos junto ao Ministério da Saúde. Além disso, os resultados obtidos confirmam que a análise microbiológica do produto final é um instrumento essencial de validação e verificação das Boas Práticas de Fabricação (BPF) e da Análise de Perigos e Pontos Críticos de Controle (APPCC).

Palavras-chave: Doenças transmitidas por alimentos (DTA), controle de qualidade, Staphylococcus aureus, Escherichia coli

\begin{abstract}
The aim of this study was to analyze the sanitary quality of foods commercialized in Londrina, Paraná that are exempt of Brazilian Health Ministry registration procedures, according to Resolution $n^{\circ} .23$ from the National Sanitary Administration Agency (ANVISA). The food categories analyzed were chosen according to ANVISA, Londrina, PR which took the epidemiological risk in account. Microbiological standards were evaluated according to ANVISA Resolution $\mathrm{n}^{\circ}$. 12. Escherichia coli and coagulase positive Staphylococcus counts were above standards in $11(18.3 \%)$ and $13(21.6 \%)$ of food samples analyzed, respectively. The others microbiological results were in conformity to ANVISA Resolution $\mathrm{n}^{\circ}$. 12. These results indicate inadequate sanitary conditions during food processing especially for ice-
\end{abstract}

\footnotetext{
1 Mestranda do Programa de Pós-graduação em Ciência dos Alimentos, Departamento de Tecnologia de Alimentos e Medicamentos (TAM), Centro de Ciências Agrárias (CCA), Universidade Estadual de Londrina (UEL), Brasil.

2 Aluna de graduação de Farmácia, bolsista de iniciação científica (PIBIC/CNPq), TAM, CCA, UEL, Londrina, PR, Brasil.

3 Professora Dra. Departamento de Tecnologia de Alimentos e Medicamentos, CCA, UEL, Londrina PR, Brasil. E-mail: terezaoliveira@yahoo.com

* Autor para correspondência
} 
cream, stuffed pasta, "pães de queijo", lasanha, cream felled pastries, and "salgado recheado". The results could help the State and Local Sanitary Administration Agencies to evaluate the potentiality of these foods cause food-borne diseases and the adequacy of their liberation from Brazilian Health Ministry registration procedures. The results also show that microbiological analysis of the final product is a valuable validation and verification procedure for the GMP and HACCP system.

Key words: Food-borne diseases, quality control, Staphylococcus aureus, Escherichia coli

\section{Introdução}

Muitos países, incluindo o Brasil, estão adotando medidas que assegurem o suprimento de alimentos inócuos. Um exemplo disto é a obrigatoriedade da implantação do sistema de Análise de Perigos e Pontos Críticos de Controle (APPCC) nas indústrias de alimentos (UNNEVEHR; JENSEN, 1999; TENT, 1999; DeWAAL, 2003). Além disso, recentemente, foram editadas no Brasil resoluções e portarias que regulamentam a produção e comercialização de alimentos, sendo que a maioria delas foram publicadas a partir de 1998 .

A RDC n. 23, de 15 de março de 2000 (BRASIL, 2000), que aprovou o Regulamento Técnico sobre o Manual de Procedimentos Básicos para Registro e Dispensa da Obrigatoriedade de Registro de Produtos Pertinentes à Área de Alimentos, da Agência Nacional de Vigilância Sanitária (ANVISA) foi editada com a finalidade de sanar problemas referentes aos alimentos por ela elencados, tanto no âmbito da produção e comercialização, quanto no controle dos referidos alimentos. Antes da sua edição, vigorava a Portaria n. ${ }^{\circ} 120$ do Ministério da Saúde, que estabelecia diversas formalidades para o cadastramento e registro de produtos alimentícios, entre elas, a análise laboratorial obrigatória antes da comercialização.

As dificuldades para o registro eram muitas, pois para cada tipo de alimento produzido por uma empresa, mesmo que se tratasse de simples modificação de um alimento já registrado, exigia-se um novo registro, com todos os trâmites legais e pagamento de nova taxa. Essas formalidades levavam ao desestímulo à produção, bem como, a um aumento da clandestinidade, que era seguida de um descontrole por parte dos órgãos fiscalizadores.
Diante dessa situação, o Ministério da Saúde realizou um levantamento epidemiológico dos alimentos que apresentavam menor risco à saúde da população por não serem veículos potenciais de enfermidades. Como resultado deste levantamento, foi editada a RDC n. ${ }^{2} 23$ da ANVISA que apresenta 45 categorias de alimentos que devem ser, obrigatoriamente, cadastrados junto ao Ministério da Saúde, porém exigindo apenas que o estabelecimento produtor tenha alvará de funcionamento, licença sanitária e preencha o formulário de cadastramento constante no Anexo X da RDC n. 23.

Após a edição da RDC n. ${ }^{\circ} 23$, não tem sido realizado, em Londrina, análise laboratorial sistemática de alimentos produzidos e comercializados que, anteriormente por lei, somente podiam ser comercializados após a realização de determinadas análises para fins de registro.

O objetivo deste trabalho foi avaliar o padrão higiênico-sanitário de alimentos comercializados na Região de Londrina cadastrados no Ministério da Saúde, porém, dispensados de registro, conforme a RDC n. ${ }^{\circ 23}$ da ANVISA, tendo como parâmetro a RDC n. ${ }^{\circ} 12$ de 2 de janeiro de 2001 da ANVISA (BRASIL, 2001).

\section{Materiais e Métodos}

\section{Categoria de alimentos analisados}

As cinco categorias de alimentos e produtos analisados neste trabalho estão apresentadas na Tabela 1. As categorias dos alimentos foram escolhidas de acordo com as sugestões da Vigilância Sanitária de Londrina, PR, que levou em consideração o risco epidemiológico, ou seja, alimentos que continham ingredientes de origem 
animal. A razão para a análise microbiológica de produtos da categoria doce foi o fato da maioria das fábricas não possuírem as Boas Práticas de Fabricação implantada. Três diferentes produtos de cada categoria foram analisados, sendo duas marcas diferentes para cada produto, contabilizando um total de seis amostras para cada categoria. Cada produto foi analisado duas vezes, com um intervalo médio de quatro meses entre uma análise e outra.

Tabela 1. Categorias e produtos alimentícios analisados.

\begin{tabular}{ll}
\hline Categoria & Produto \\
\hline Doce & $\begin{array}{l}\text { Doce de leite } \\
\text { Doce de abóbora } \\
\text { Paçoca (doce de amendoim) }\end{array}$ \\
\hline Gelados & Sorvete de chocolate \\
& Sorvete de creme \\
& Sorvete de morango \\
\hline Massas & Frescas \\
& Recheada com produtos de origem animal \\
& Recheadas com produtos mistos (origem animal e vegetal) \\
\hline Congelados & Pão de queijo \\
& Salgados recheados com produtos de origem animal \\
& Lasanha \\
\hline Produtos de confeitaria & Salgados recheados com produtos de origem animal \\
& Doces com creme \\
& Bolo sem recheio \\
\hline
\end{tabular}

\section{Preparo das amostras para análise microbiológica}

Alíquotas de $25 \mathrm{~g}$ de cada amostra de alimento foram pesadas assepticamente e homogeneizadas (Seward Stomacher 400 Lab System, Inglaterra) durante 1 minuto com 225,0 mL de água peptonada 0,1\% (Merck, São Paulo, SP, Brasil) (SILVA; JUNQUEIRA; SILVEIRA, 1997).

Diluições decimais, a partir da diluição $10^{-1}$, foram preparadas em tubos contendo $9,0 \mathrm{~mL}$ de água peptonada $0,1 \%$ (Merck).

Contagem de coliformes totais e Escherichia coli

O método Petrifilm ${ }^{\mathrm{TM}}$ EC (3M Company, St. Paul, MN, Estados Unidos) foi utilizado para a contagem de coliformes totais e Escherichia coli, seguindo as instruções do fabricante.

\section{Contagem de bolores e leveduras}

Alíquotas de 1,0 mL das diluições preparadas conforme "Preparo das Amostras para Análise Microbiológica" foram transferidas para placas estéreis e adicionado o meio Ágar Batata Dextrose (Acumedia Manufacturers, Inc., Baltimore, MD, Estados Unidos), pH 3,5 acidificado com ácido tartárico $1,0 \%$. As placas foram incubadas a $25^{\circ} \mathrm{C}$ e após 5 dias realizada a contagem de unidades formadoras de colônias (UFC) (SILVA; JUNQUEIRA; SILVEIRA, 1997).

\section{Detecção de Salmonella spp}

Alíquotas de 25,0g dos diferentes alimentos analisados foram cultivadas em $225,0 \mathrm{~mL}$ de água peptonada alcalina $1,0 \%$ (Merck) a $35^{\circ} \mathrm{C}$ por 24 horas. Após o pré-enriquecimento, $1,0 \mathrm{~mL}$ foi transferido 
para 10,0mL de caldo Selenito-cistina (Biobrás S.A., Montes Claros, MG, Brasil) e 0,1 mL para $10,0 \mathrm{~mL}$ de caldo Rappaport-vassiliadis R10 Broth (Acumedia). Os tubos foram incubados respectivamente a $35^{\circ} \mathrm{C}$ e $42^{\circ} \mathrm{C}$. Após 24 horas, foi realizado plaqueamento seletivo diferencial em Ágar Xilose Lisina Desoxicolato (Biobrás S.A.). As placas foram incubadas a $35^{\circ} \mathrm{C}$ e após 24 horas realizada identificação bioquímica de colônias características de Salmonella spp empregando-se os meios de citrato Simmons (Biobrás S.A.), rugai e mili (OLIVEIRA et al., 1997).

\section{Contagem de clostrídio sulfito redutores}

Alíquotas de 1,0 mL das diluições, preparadas conforme item 2.2., foram transferidas para placas estéreis, adicionado-se o meio Ágar Shahidi Ferguson Perfringens (Merck). Após 72 horas de incubação em anaerobiose a $37^{\circ} \mathrm{C}$, foi feita a contagem das unidades formadoras de colônias (UFC) sulfito redutoras e identificação bioquímica empregando-se os meios de leite e ferro, ágar nitrato motilidade e meio lactose gelatina (SIQUEIRA, 1995).

\section{Contagem de estafilococos coagulase positiva}

Alíquotas de 0,1 mL das diluições, preparadas conforme "Preparo das amostras para análise microbiológica", foram semeadas sobre a superfície do meio Baird-Parker (Acumedia). As placas foram incubadas a $37^{\circ} \mathrm{C}$ e após 48 horas foi realizada a contagem de unidades formadoras de colônias e identificação de colônias pretas, com anel branco opaco rodeado por um halo claro transparente destacando-se sobre a opacidade do meio, características de Staphylococcus spp. A prova da coagulase foi realizada com 3 a 4 colônias características (SIQUEIRA, 1995).

\section{Contagem de Bacillus cereus}

Alíquotas de 0,1 $\mathrm{mL}$ das diluições, preparadas conforme "Preparo das amostras para análise microbiológica", foram semeadas sobre a superfície do meio Agar Polimixina Manitol Gema de Ovo Vermelho de Fenol (Vetec Química Fina Ldta., Duque de Caxias, MG, Brasil). As placas foram incubadas a $30^{\circ} \mathrm{C}$ e após 24 horas foi feito a contagem de unidades formadoras de colônias e selecionadas colônias esféricas, com bordas perfeitas, planas, secas e rosadas, rodeadas por halo branco, características de B. cereus. Colônias características isoladas foram identificadas empregando-se a redução do nitrato, hidrólise do amido e da gelatina (SIQUEIRA, 1995).

Determinação da atividade de água (Aa)

A atividade de água foi determinada utilizandose equipamento da marca Aqualab, modelo CX-2, seguindo-se as recomendações do fabricante quanto ao funcionamento e calibração.

\section{Resultados e Discussão}

Os resultados das análises microbiológicas dos alimentos analisados neste trabalho e que estavam em desacordo com a RDC n. ${ }^{\circ} 23$ da ANVISA estão apresentados na Tabela 2.

Das 60 amostras analisadas, $11(18,3 \%)$ e 13 $(21,6 \%)$ apresentavam, respectivamente, contagens de Escherichia coli e estafilococos coagulase positiva acima do permitido. Os demais resultados microbiológicos estavam dentro do padrão estabelecido pela legislação brasileira para todas as categorias de alimentos testados.

\section{Categoria doce}

Nenhuma das amostras de produtos da categoria doce apresentaram desenvolvimento bacteriano nas análises realizadas. Os resultados mostraram que a atividade de água (aw), variando entre 0,592 para doce de amendoim e 0,893 para doce vegetal em pasta foi o fator determinante para a obtenção desses resultados.

Em um estudo realizado pelo INMETRO (INSTITUTO NACIONAL DE METROLOGIA, 
1996) com amostras de pé de moleque, paçoca e cocada, embora as contagens de bolores tenham sido baixas, foi detectada a presença de aflatoxina acima dos limites tolerados pela legislação, tornando o alimento inapropriado ao consumo humano. Este fato alerta para a necessidade de se fazer a pesquisa de micotoxinas neste tipo de alimento, que ao contrário dos bolores são termoestáveis, podendo permanecer no produto mesmo após tratamento térmico.

A RDC n. ${ }^{\circ} 12$ da ANVISA não exige a pesquisa de estafilococos coagulase positiva para os produtos da categoria doce. Porém, Staphylococcus spp. pode se multiplicar e produzir enterotoxinas em alimentos com aw de 0,86 (HALPIN-DOHNALEK; MARTH, 1989). O fato de não ter havido desenvolvimento microbiano nas amostras analisadas, reforça a possibilidade do crescimento de estafilococos, que são maus competidores. Portanto, a aw de 0,893 do doce vegetal em pasta analisado neste trabalho não seria uma barreira para o desenvolvimento dessa bactéria.

\section{Gelados comestiveis}

Cepas de E. coli foram isoladas em $50 \%$ das amostras de gelados comestíveis analisadas com contagens acima do estabelecido pela legislação (Tabela 2). Outros autores relataram a detecção de coliformes de origem fecal em sorvetes com contagens semelhantes às obtidas neste trabalho (PINTO et al., 2000; ARMONDES et al., 2003; KANBAKAN; ÇOM; AYAR, 2004). É importante salientar que todas as amostras de sorvete de uma mesma empresa apresentavam E. coli acima do padrão. Esses resultados sugerem que, ou a pasteurização da massa do sorvete não foi suficiente para diminuir a contagem de E. coli devido à alta contaminação das matérias primas utilizadas, ou que houve a contaminação do produto pós-processamento.

A presença de E. coli, que é o melhor indicador de contaminação fecal, indica a possibilidade da presença de outros patógenos intestinais. A maioria das pessoas acredita que os sorvetes são inócuos por serem conservados $\mathrm{a}-15^{\circ} \mathrm{C}$. Porém, embora as bactérias patogênicas não se multipliquem nessa temperatura, podem permanecer viáveis por longos períodos e serem veiculadas ao consumidor, uma vez que os gelados comestíveis são consumidos sem nenhum processamento que possa destruir essas bactérias.

A ausência de estafilococos coagulase positiva nos gelados comestíveis analisados neste estudo é explicada pelo fato de o processamento desses alimentos não necessitar da manipulação direta do homem, principal fonte de contaminação. Por outro lado, o isolamento de $S$.aureus em contagens elevadas observado por outros autores alerta para o risco potencial deste produto. Armondes et al. (2003) observaram a presença de Staphylococcus aureus em $10 \%$ das amostras de sorvete analisadas, com contagens variando entre $1,1 \times 10^{3} \mathrm{e} 1,0 \times 10^{4} \mathrm{UFC} /$ g. Eleftheriadou et al. (2002) isolaram $S$. aureus em $4 \%$ das amostras de gelados comestíveis analisados com contagens maiores que $10^{4} \mathrm{UFC} / \mathrm{g}$.

\section{Massas frescas}

Contagens de E. coli acima do limite máximo estabelecido foram encontradas em todas as amostras de uma mesma marca de "massa recheada mista" (Tabela 2), correspondendo a 50\% das amostras analisadas. Condições higiênico-sanitárias insatisfatórias parecem estar estabelecidas, uma vez que os mesmos resultados foram observados nas duas análises realizadas com intervalos de quatro meses. Embora as massas sejam consumidas após o processamento térmico, que elimina o risco de veiculação de bactérias patogênicas, o consumidor tem o direito de adquirir um alimento produzido seguindo as Boas Práticas de Fabricação.

Contagens de estafilococos coagulase positiva acima de 5,0 × $10^{3} \mathrm{UFC/g}$, contagem máxima estabelecida pela RDC n. ${ }^{\circ} 12$, foram observadas em $50 \%$ das amostras de massa recheada com produto de origem animal (Tabela 2). Todas as amostras de massa recheada mista apresentavam contagens de estafilococos coagulase positiva abaixo do limite 

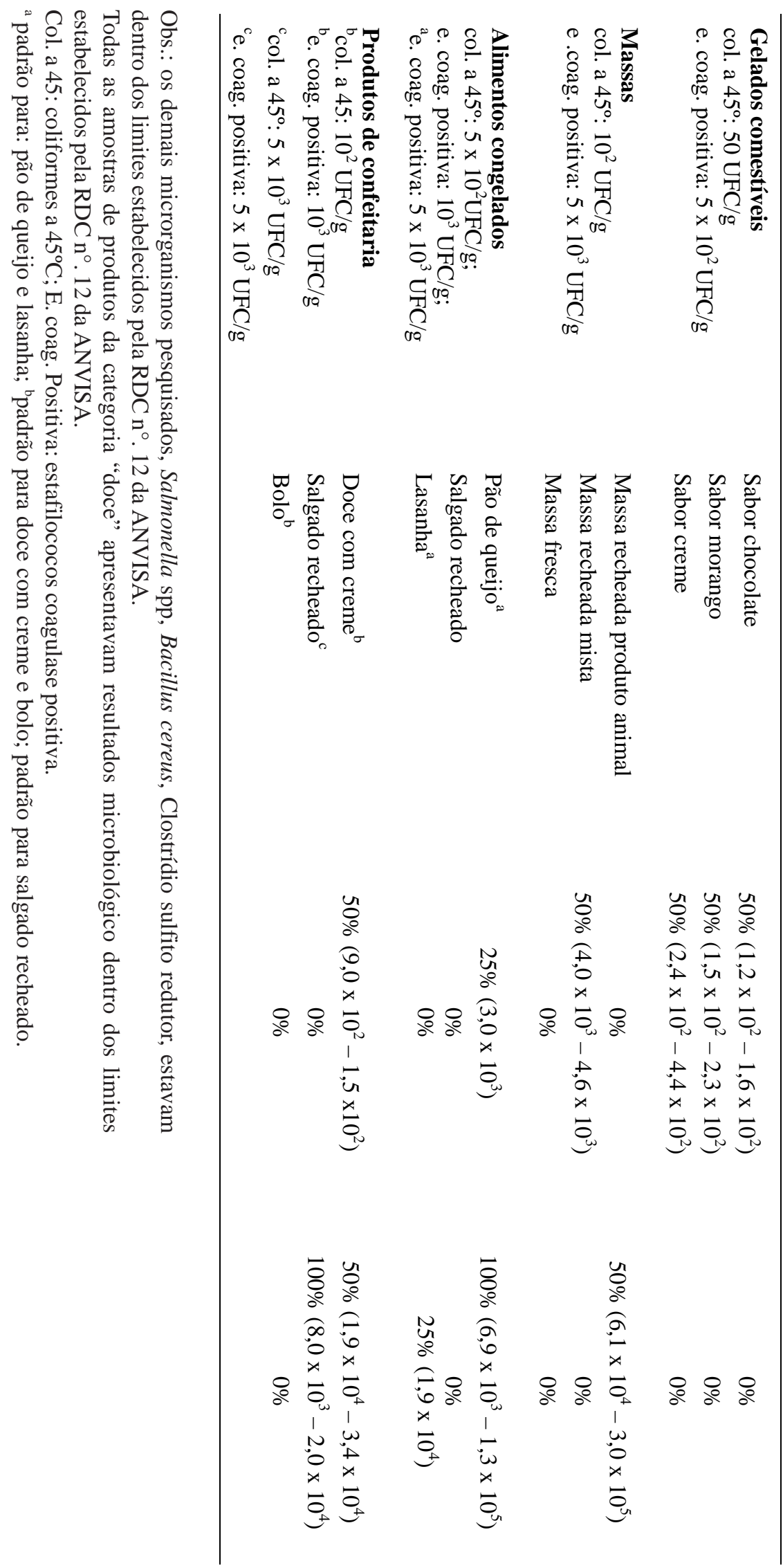

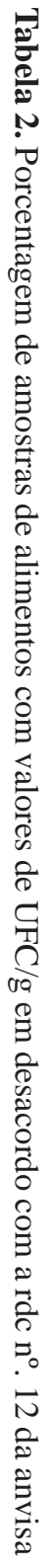


permitido, porém, 50\% das amostras estavam contaminadas, nas duas etapas de análise, com uma contagem média de 3,7 x $10^{3} \mathrm{UFC} / \mathrm{g}$, contagem alta para um microrganismo potencialmente patogênico.

Segundo a INTERNATIONAL COMISSION ON MICROBIOLOGICAL SPECIFICATIONS FOR FOODS- ICMSF, (1980) e o FOOD AND DRUG ADMINISTRATION - FDA, (1992), a contagem de $S$. aureus entre $10^{3}$ a $10^{4} \mathrm{UFC} / \mathrm{g}$ indica risco à saúde pública. Valores próximos a $10^{5} \mathrm{UFC/}$ g significam risco epidemiológico devido à possibilidade da presença de enterotoxinas em quantidade suficiente para causar intoxicação estafilocócica se a cepa de $S$. aureus for toxigênica.

Cepas de $S$. aureus tem sido detectados com freqüência em produtos de origem animal ou submetidos à manipulação inadequada (CUNHA NETO; SILVA; STAMFORD, 2002; SORIANO et al., 2002) devido a contaminação humana pósprocessamento, já que, este microrganismo tem como ambiente natural o vestíbulo nasal de seres humanos (ACCO et al., 2003; YUSTE; FUNG, 2003; SANDEL; McKILLIP, 2004). Portanto, a contaminação dos alimentos, geralmente, ocorre pelo manipulador. Os resultados obtidos neste trabalho para massa recheada mista e, principalmente, para massa recheada com produto de origem animal alertam para a necessidade da implantação urgente de Boas Práticas de Fabricação nos estabelecimentos que preparam estes produtos, visto que, $S$. aureus pode produzir enterotoxinas termorresistentes que podem não ser destruídas pelo processamento térmico utilizado antes do consumo.

A possibilidade de massas causarem intoxicação estafilocócica foi alertada por Cunha Neto, Silva e Stamford (2002), que observaram presença de $S$. aureus com contagens variando entre $5,0 \times 10^{2}$ a 1,1 x $10^{4} \mathrm{UFC} / \mathrm{g}$, inclusive com detecção de enterotoxinas no alimento. Eleftheriadou et al. (2002) relataram o isolamento de $S$. aureus com contagens superiores a $10^{4} \mathrm{UFC} / \mathrm{g}$ em $23 \%$ das amostras de ravióli recheado com produto de origem animal analisadas. A contaminação foi atribuída à manipulação excessiva durante o preparo. Um surto alimentar de intoxicação estafilocócica ocorrido na Espanha foi associado à massa fresca recheada, acometendo 581 pessoas (MATUTE; MARTINEZ, 1997).

\section{Alimento congelado}

Todas as amostras de lasanha e salgados recheados apresentaram contagens de E. coli dentro dos limites estabelecidos pela legislação.

Das amostras de pão de queijo analisadas, uma estava acima do limite máximo estabelecido para $E$. coli, na segunda etapa do estudo (Tabela 2). As demais estavam dentro do padrão com contagens variando entre 60 e $120 \mathrm{UFC} / \mathrm{g}$.

Outros trabalhos realizados com pão de queijo mostraram condições inadequadas de processamento deste produto. Pinto et al. (2000) analisaram as condições fabris de uma indústria de pão de queijo e encontraram que $45,8 \%$ dos equipamentos utilizados apresentavam contagens elevadas de coliformes fecais, indicando ineficiência do processo de higienização dos equipamentos e utensílios.

Em uma avaliação de contaminação de pães de queijo realizada pelo INSTITUTO NACIONAL DE METROLOGIA (1998), das 11 marcas analisadas, sete, foram classificadas como "impróprias para o consumo", devido à presença de coliformes fecais com contagens maiores que $10^{2} \mathrm{UFC} / \mathrm{g}$.

Todas as amostras de pães de queijo analisadas neste trabalho estavam contaminadas com estafilococos coagulase positiva acima do padrão estabelecido pela ANVISA (Tabela 2), apesar de todas as amostras serem comercializadas congeladas. As contagens elevadas indicam risco potencial deste produto causar agravo à saúde se durante o preparo ou armazenamento houver condições de produção de enterotoxinas, que devido à termoestabilidade poderão permanecer ativas após o produto ser assado para consumo.

Uma amostra de uma das marcas de lasanha analisadas na primeira etapa deste trabalho estava contaminada com contagem $1,9 \times 10^{4} \mathrm{UFC} / \mathrm{g}$ de 
estafilococos coagulase positiva. Esses resultados mostram que a manipulação inadequada, provavelmente, não está instalada de forma permanente na empresa, já que na segunda etapa de análise a mesma marca apresentou contagens menores que $1,0 \times 10^{1} \mathrm{UFC} / \mathrm{g}$.

\section{Produtos de confeitaria}

Todas as amostras de bolo estavam dentro do padrão microbiológico estabelecido pela RDC n. ${ }^{\circ} 12$.

Uma das marcas de doce com creme analisada, durante as duas etapas deste estudo, apresentou contagem de $E$. coli e estafilococos coagulase positiva acima do estipulado pela legislação (Tabela 2).

Eleftheriadou et al. (2002) encontraram em doces de confeitaria contagens para E. coli maiores que 100 $\mathrm{UFC} / \mathrm{g}$, sendo o quarto alimento mais contaminado dentre vários outros analisados. Esses mesmos autores observaram que das 2402 amostras de produtos de confeitaria analisadas, $6 \%$ estavam contaminadas com Staphylococcus aureus, com contagens maiores que $10^{4}$ UFC/g. Marsiglia, Garbelotti e De Paula (1997) também encontraram 5\% das 101 amostras de produtos de confeitaria em desacordo com a legislação para Staphylococcus aureus.

Estafilococos coagulase positiva foram detectados em 100\% dos salgados recheados analisados (Tabela 2). Esses resultados precisam ser ressaltados uma vez que esses produtos foram da mesma procedência daqueles comercializados congelados prontos para consumo e incluídos na categoria alimento congelado. Este fato mostra claramente que a empresa apresenta condições higiênico-sanitárias inadequadas de processamento e alerta para o risco potencial, dependendo da maneira como o alimento venha a ser comercializado. Nos salgados fritos e congelados não houve detecção de estafilococos coagulase positiva (Tabela 2), porém, isto não isenta o produto do risco uma vez que a enterotoxina estafilocócica é termoestável e pode estar ativa independente da presença de células viáveis.
Voos et al. (2000) encontraram, para salgados recheados contagens de Staphylococcus aureus variando entre $1,0 \times 10^{1}$ e $2,5 \times 10^{5} \mathrm{UFC} / \mathrm{g}$. Do total de amostras analisadas, 43,04\% foram consideradas com condições higiênico-sanitárias insatisfatórias e $13,04 \%$ com potencial capacidade de causar intoxicação alimentar por apresentar contagens de Staphylococcus aureus maiores que $10^{4} \mathrm{UFC} / \mathrm{g}$. Por outro lado, Hoffmann, Garcia-Cruz e Vinturin (1999) ao analisarem amostras de salgado recheado encontraram contagens de Staphylococcus aureus não superiores a 2,0 x $10^{2} \mathrm{UFC} / \mathrm{g}$, ou seja, dentro do limite estabelecido pela legislação brasileira. Porém, os autores não mencionaram se os produtos haviam sido processados termicamente antes da análise.

\section{Conclusões}

Contagens de E. coli e $S$. aureus acima do estabelecido pela RDC $\mathrm{n}^{\circ} .12$ da ANVISA foram observadas respectivamente em 18,3 e 21,6\% dos 60 alimentos analisados. Os demais resultados microbiológicos estavam dentro dos limites estabelecidos pela RDC $n^{\circ}$. 12. Ficou clara a necessidade de maior fiscalização das condições de preparo, manipulação e armazenagem de vários dos alimentos analisados, em especial, sorvetes, massa recheada com produto animal, pão de queijo, lasanha, doce com creme e salgados recheados. Esses resultados serão encaminhados às Vigilâncias Regional e Municipal alertando sobre potencialidade desses alimentos veicularem doenças e na intenção de abrir uma discussão sobre a possibilidade de esses alimentos serem ou não liberados de registro junto ao Ministério da Saúde. Além disso, os resultados obtidos confirmam que mesmo com a implementação de BPF e do sistema APPCC, a análise microbiológica do produto final é um instrumento essencial de validação e verificação das condições higiênico-sanitárias de processamento de alimentos. 


\section{Agradecimentos}

À Coordenação de Aperfeiçoamento de Pessoal de Nível Superior pela bolsa de mestrado concedida à Rafaela Gomes Ferrari. Ao Conselho Nacional de Desenvolvimento Científico e Tecnológico (CNPq) pela bolsa de iniciação científica (PIBIC) concedida à Sabine Murakami Winkler. À Secretaria de Saúde do Município de Londrina pelas sugestões quanto às categorias de alimentos analisadas.

\section{Referências}

ACCO, M.; FERREIRA, F. S.; HENRIQUES, J. A. P.; TONDO, E. C. Identification of multiple strains, of Staphylococcus aureus colonizing nasal mucosa of food handles. Food Microbiology, London, v.20, n.5, p.489493 , oct. 2003.

ARMONDES, M. P.; ISSY, P. N.; ANDRÉ, M. C. D. P. B.; SERAFINI, A. B. Aspectos higiênico- sanitário de sorvetes e caldas de sorvetes produzidos artesanalmente na cidade de Goiânia, GO. Revista Higiene Alimentar, São Paulo, v.17, n.107, p.86-94, 2003.

BRASIL. Agência Nacional de Vigilância Sanitária. Resolução n. ${ }^{\circ} 23$ de 16 de março de 2000. Disponível em: <http://www.anvisa.gov.br/legis/resol/2000/ 23_00.htm>. Acesso em: 17 nov. 2006.

Resolução n. ${ }^{o} 12$ de 2 de janeiro de 2001. Disponível em: <http://www.anvisa.gov.br/legis/resol/ 12_01rdc.htm>. Acesso em: 14 ago. 2006.

CUNHA NETO, A.; SILVA, C. G. M.; STAMFORD, T. L. M. Staphylococcus enterotoxigênicos em alimentos in natura e processados no estado de Pernambuco, Brasil. Ciência e Tecnologia de Alimentos, Campinas, v.22, n.3, p.263-271, 2002.

DeWAAL, C. S. Safe food from a consumer perspective. Food Control, Guildford, v.14, n.2, p.75-79, mar. 2003.

ELEFTHERIADOU, M.; VARNAVA-TELLO, A.; METTALOIZIDOU, M.; NIKOLAOU, A.; AKKELIDOU, D. The microbiological profile of foods in the Republic of Cyprus: 1991-2000. Food Microbiology, London, v.19, n.5, p.463471, 2002.

FOOD AND DRUG ADMINISTRATION. Foodborne pathogenic microorganisms and natural toxins handbook. 1992. Disponível em: < http:// www.cfsan.fda.gov/ mow/chap3.html>. Acesso em: 12 set. 2006.
HALPIN-DOHNALEK, M. I.; MARTH, E. H. Staphylococcus aureus: production of extracellular compounds and behavior in foods: a review. Journal of Food Protection, Des Moines, v.52, n.4, p.267-282, 1989.

HOFFMANN, F. L.; GARCIA-CRUZ, C. H.; VINTURIM, T. M. Estudo higiênico-sanitário de amostras de diferentes produtos cárneos Revista Higiene Alimentar, São Paulo, v.13, n.63, p.43-47, 1999.

INSTITUTO NACIONAL DE METROLOGIA. 1996. Disponível em: <http://www.inmetro.gov.br/consumidor/ prodAnalisados.asp>. Acesso em: 30 jan. 2005.

INSTITUTO NACIONAL DE METROLOGIA. 1998. Disponível em: <http://www.inmetro.gov.br/consumidor/ prodAnalisados.asp>. Acesso em: 30 de janeiro de 2005.

INTERNATIONAL COMISSION ON MICROBIOLOGICAL SPECIFICATIONS FOR FOODS. Ecologia microbiana de los alimentos. Zaragoza: Acribia, 1980. v.1, p.1-38.

KANBAKAN, U.; ÇOM, A. H.; AYAR, A. Determination of microbiological contamination sources during ice cream production in Denizli, Turkey. Food Control, Guildford, v.15, n.6, p.463-470, 2004.

MARSIGLIA, D. A. P.; GARBELOTTI, M. L.; DEPAULA, A. M. R. Controle da qualidade microbiológica e físicoquímica de doces de confeitaria. Revista Higiene Alimentar, São Paulo, v.48, n.11, p.45-48, 1997.

MATUTE, P.; MARTINEZ, J. F. Outbreak of food poisoning due to Staphylococcus aureus on the island of Tenerife. Journal of Clinical Epidemiology, New York, v.50, n.1, p.31, 1997.

OLIVEIRA, T. C. R. M.; SVIDZINSKI, T. I. E.; HERRERO, F.; CARDOSO, R. F.; SIQUEIRA, V.L. D.; MARCONDES, N. R. Manual de aulas práticas. Maringá: Universidade Estadual de Maringá, 1997.

PINTO, M. F.; PONSANO, E. H. G.; DELBEM, A. C. B.; DE LARA, J. A. F. Condição higiênico-sanitária de sorvetes fabricados por indústrias artesanais no município de Araçatuba, SP. Revista Higiene Alimentar, São Paulo, v.14, n.72, p.50-52, 2000.

SANDEL, M. K.; McKILLIP, J. L. Virulence and recovery of Staphylococcus aureus relevant to the food industry using improvements on traditional approaches. Food Control, Guildford, v.15, n.1, p.5-10, 2004.

SILVA, N.; JUNQUEIRA, V. C. A.; SILVEIRA, N. F. A. Manual de métodos de análise microbiológica de alimentos. São Paulo: Livraria Varela, 1997.

SIQUEIRA, R. S. Manual de microbiologia de alimentos. Brasília: EMBRAPA, 1995. p.73-153. 
SORIANO, J. M.; FONT, G.; MOLTO, J. C.; MAÑES, J. Enterotoxigenic staphylococci and their toxins in restaurant foods. Trends in Food Science \& Technology, Guildford, v.13, n.2, p.60-67, 2002.

TENT, H. Research on food safety in the $21^{\text {st }}$ century. Food Control, Guildford, v.10, n.4, p.239-241, 1999.

UNNEVEHR, L. J.; JENSEN, H. H. The economic implications of using HACCP as a food safety regulatory standard. Food Policy, Guildford, v.24, n.6, p.625-635, dec. 1999.
VOOS, I. S. P.; ROSA, O. O.; BERRAR, R. A.; BETT, S. C. Controle de qualidade microbiológica em produtos de confeitaria preparados e congelados. Revista Higiene Alimentar, São Paulo, v.14, n.68/69, p.78-86, 2000.

YUSTE, J.; FUNG, D. Y. C. Evaluation of Salmonella typhimurium, Yersinia enterocolitica and Staphylococcus aureus counts in apple juice with cinnamon, by conventional media and thin agar layer method. Food Microbiology, London, v.20, n.3, p.365$370,2003$. 